\title{
New $\alpha$-Hydroxy-1,2,3-triazoles and 9H-Fluorenes-1,2,3-triazoles: Synthesis and Evaluation as Glycine Transporter 1 Inhibitors
}

\author{
Veronica D. da Silva, ${ }^{a}$ Rafaela R. Silva,${ }^{b}$ João Gonçalves Neto, ${ }^{a}$ Beatriz López-Corcuera, ${ }^{c, d}$ \\ Marilia Z. Guimarães, ${ }^{e}$ François Noël ${ }^{b}$ and Camilla D. Buarque ${ }^{\circledR} * a$
}

${ }^{a}$ Laboratório de Síntese Orgânica, Pontifícia Universidade Católica do Rio de Janeiro, 22451-900 Rio de Janeiro-RJ, Brazil

${ }^{b}$ Laboratório de Farmacologia Bioquímica e Molecular, Instituto de Ciências Biomédicas, Universidade Federal do Rio de Janeiro, 21941-901 Rio de Janeiro-RJ, Brazil

'Departamento de Biología Molecular, Universidad Autónoma de Madrid, 28049 Madrid, Spain

${ }^{d}$ Centro de Biología Molecular, "Severo Ochoa" Consejo Superior de Investigaciones Científicas, Universidad Autónoma de Madrid, 28049 Madrid, Spain

'Instituto de Ciências Biomédicas, Universidade Federal do Rio de Janeiro, 21941-901 Rio de Janeiro-RJ, Brazil

\begin{abstract}
Two series of new compounds containing 1,2,3-triazole moiety were designed as putative GlyT1 inhibitors aiming the discovery of new hits with activity in cognitive disorders. 1,4-Disubstituted $\alpha$-hydroxy-1,2,3-triazoles were obtained as racemates in moderate to good yields by the copper-catalyzed azide-alkyne cycloaddition (CuAAC) reaction (click chemistry) as the key step between propargyl alcohols and aryl azides, previously prepared from anilines or boronic acids. Benzo $[c]$ chromene-triazoles were planned to be obtained by palladium-catalyzed $\mathrm{C}-\mathrm{H}$ activation using [bis(trifluoroacetoxy)iodobenzene] (PhI(TFA) $)_{2}$ ) of some $\alpha$-hydroxy-1,2,3-triazoles, since benzo $[c]$ chromenes are also privileged groups with several biological activities, including to the central nervous system. Unexpectedly, $9 H$-fluorenes-1,2,3-triazoles, instead of benzo[ $c]$ chromenetriazoles, were obtained by Friedel-Crafts alkylation reaction. The two series of compounds were tested for inhibition of the glycine transporter (rat GlyT1 isoform) but only the $\alpha$-hydroxy1,2,3-triazole $\mathbf{9 b}$ was active (half maximal inhibitory concentration $\left(\mathrm{IC}_{50}\right)=8.0 \mu \mathrm{M}$ ).
\end{abstract}

Keywords: 1,4-disubstituted-1,2,3-triazoles, 9H-fluorenes-1,2,3-triazoles, click chemistry, Friedel-Crafts alkylation, schizophrenia, glycine transport

\section{Introduction}

Several compounds containing the 1,2,3-triazole moiety have pharmacological properties potentially useful for antifungal and antibacterial, ${ }^{1}$ anticancer ${ }^{2}$ and antiviral ${ }^{3}$ therapy and, in some cases, for the treatment of mental disorders including depression, anxiety, schizophrenia and epilepsy. ${ }^{4,5}$

Different reports indicate that triazoles have affinity not only for dopaminergic, adrenergic and serotonergic receptors ${ }^{4,6}$ but also inhibit the glycine transporter GlyT1, considered as an important target for the treatment of schizophrenia, cognitive disorders, alcohol dependence and

*e-mail: camilla-buarque@puc-rio.br pain. ${ }^{7-9}$ Figure 1 shows some examples of GlyT1 inhibitors such as ALX 5407 (1), a potent, selective and irreversible compound ${ }^{10}$ without clinical use but largely employed as a pharmacological tool.

Bitopertin (2) (Hoffmann-La Roche) was the first of the non-sarcosine derivative GlyT1 inhibitors to be tested in schizophrenia preclinical models and phase II and III clinical trials. ${ }^{11}$ This compound is a potent and selective non-competitive inhibitor of the GlyT1 subtype and does not act on other molecular targets. ${ }^{12}$ Among the compounds containing a triazole moiety, methyl-1,2,3-triazole 3 stands out since it is a non-competitive inhibitor with very high potency and good metabolic stability in vitro. ${ }^{9}$ It is important to notice that among the compounds evaluated by these authors, ${ }^{9}$ the 1,2,3-triazoles were more potent than 


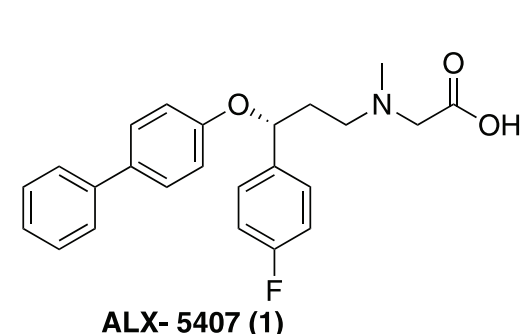

ALX- 5407 (1)<smiles>CC(Oc1ccc(S(C)(=O)=O)cc1CN1CCN(c2ncc(C(F)(F)F)cc2F)CC1)C(F)(F)F</smiles>

Bitopertin (2)<smiles>Cn1cc(S(=O)(=O)N2CC(CC3CC3)(C(=O)c3ccc(Cl)cc3Cl)C2)nn1</smiles>

(3)<smiles>OCC1CCCN(CCCC2CCCc3ccc(OCc4noc(-c5ccccc5F)n4)cc32)C1</smiles>

GlyT1 $K i=10 \mathrm{nM}$<smiles>CCc1nnc(-c2ccc(-c3ccccc3)nc2)n1-c1cccc(C#N)c1C</smiles>

(6)

GlyT1 IC $\mathrm{I0}_{50}=64 \mathrm{nM}$<smiles>Cn1cnc(C(=O)N(Cc2cccc(Cl)c2)C2CCC(N)CC2)c1</smiles>

(5)

Gly $\mathrm{T} 1 \mathrm{IC}_{50}=0.1 \mathrm{nM}$

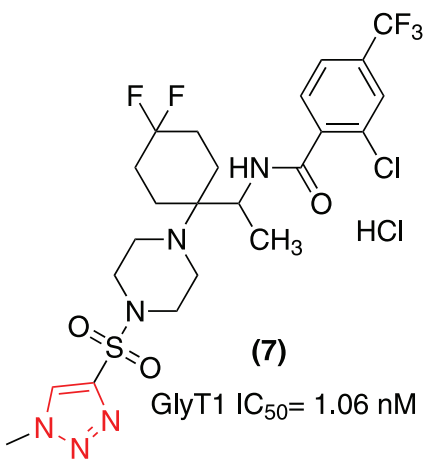

Figure 1. GlyT1 inhibitors.

the 1,2,4-triazoles. Compounds $\mathbf{4}$ and $\mathbf{5}$ were described by the Pfizer company as very potent and selective GlyT1 inhibitors. Compound $\mathbf{4}$ exhibited potent in vivo activity in the cerebral spinal fluid (CSF) glycine model, with excellent drug-like physical properties due to its lipophilicity, whereas compound $\mathbf{5}$ showed good selectivity and high affinity for the GlyT1 $\left(\mathrm{K}_{\mathrm{i}}\right.$ (inhibitor constant) $\left.=1.8 \mathrm{nM}\right) \cdot{ }^{13,14}$ New classes of the $4 H-1,2,4$-triazole derivatives were reported selective GlyT1 inhibitors. ${ }^{8}$ Compound $\mathbf{6}$ was moderately potent (half maximal inhibitory concentration $\left(\mathrm{IC}_{50}\right)=64 \mathrm{nM}$ ), had a good pharmacokinetics (PK) profile and was the most potent in the induced hyperlocomotion assay. ${ }^{8}$ More recently, it was reported ${ }^{15}$ another kind of structure based on 1,2,3-triazoles exemplified by compound 7 , with excellent inhibitory activity $\left(\mathrm{IC}_{50}=1.06 \mathrm{nM}\right)$.

The most common method for the synthesis of 1,2,3-triazole is the copper(I) catalyzed azide-alkyne $[3+2]$ cycloaddition reaction $(\mathrm{CuAAC})$, a kind of "click" reaction. ${ }^{16,17}$ In a previous work, ${ }^{18}$ we described the use of 1,2,3-triazoles as linker to combine different groups in a bifunctional molecules active for cancer human glioblastoma cells (GBM), including highly drugresistant human cell lines GBM-02 and GBM-95. In this work, we have planned new $\alpha$-hydroxy-1,2,3-triazoles and benzo $[c]$ chromene-triazoles, two other kinds of bifunctional molecules linked by the 1,2,3-triazole moiety. Unexpectedly, we obtained $9 \mathrm{H}$-fluorene linked to the 1,2,3-triazole moiety instead of benzo[c]chromenetriazoles. As $9 \mathrm{H}$-fluorenes are interesting class of polycyclic aromatic hydrocarbons that can be found in many naturally compounds and pharmaceutically active substances as well as organic materials used in the development of photoelectric devices, ${ }^{19,20}$ we decided to evaluate them together with the $\alpha$-hydroxy-1,2,3-triazoles as nonsarcosine based GlyT1 inhibitors (Figure 2).

\section{Results and Discussion}

Synthesis of $\alpha$-hidroxy-1,2,3 triazoles

The propargyl alcohols 13a-13b were obtained in two steps with good yields by cross-coupling reaction between 


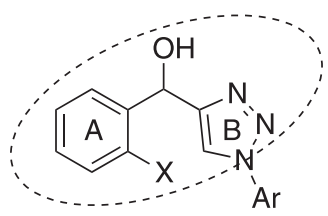

9a-h

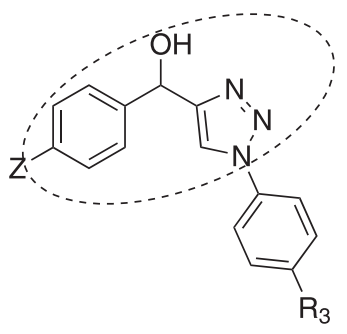

9i-j<smiles>OC(c1cn(Br)nn1)c1ccc[Y]c1-c1ccccc1</smiles>

9m-r

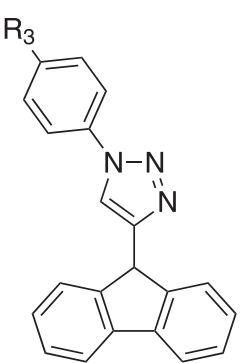

$10 a-c$

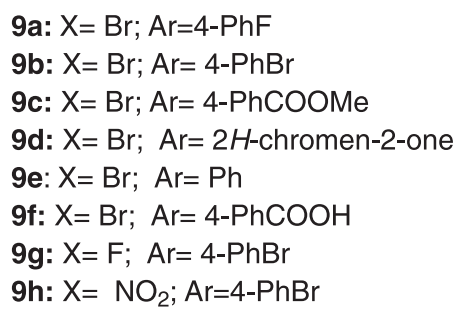

9i: $Z=B r ; R_{3}=4-B r$ 9j: $Z=H ; R_{3}=4-B r$ 9l: $Z=B r ; R_{3}=4-F$
$9 \mathrm{~m}: \mathrm{Y}=\mathrm{N} ; \mathrm{Ar}=4-\mathrm{PhCOOMe}$

9n: $Y=N ; A r=4-P h F$

9o: $\mathrm{Y}=\mathrm{CH} ; \mathrm{Ar}=2 \mathrm{H}$-chromen-2-one

9p: $\mathrm{Y}=\mathrm{CH} ; \mathrm{Ar}=4-\mathrm{PhF}$

9q: $Y=\mathrm{CH} ; \mathrm{Ar}=4-\mathrm{PhOMe}$

9r: $\mathrm{Y}=\mathrm{CH} ; \mathrm{Ar}=4-\mathrm{PhCOMe}$ 10a: $R_{3}=F$

10b: $\mathrm{R}_{3}=\mathrm{OMe}$

10c: $R_{3}=$ COMe

Figure 2. Structures of $\alpha$-hydroxy-1,2,3-triazoles and $9 H$-fluorenes-1,2,3-triazoles prepared in this work.

11a-11b and phenylboronic acid followed by addition of ethynyl trimethylsilane to the aldehydes 12a-12b (Scheme 1). On the other hand, the propargyl alcohols 13c-13g were obtained in one step by addition of ethynyl trimethylsilane to the aldehydes $\mathbf{1 2 c - 1 2 g}$ in yields ranging from 67 to $89 \%$ (Scheme 1). The lowest yields observed for compounds 13a and 13b were possibly due to the steric hindrance by the phenyl group. The characterization of the compounds was performed by ${ }^{1} \mathrm{H}$ nuclear magnetic resonance (NMR) and Fourier transform infrared spectroscopy (FTIR). The ${ }^{1} \mathrm{H}$ NMR spectrum exhibited a singlet signal at $\delta$ 5.41-5.97 ppm relative to the benzyl alcohol $(\mathrm{CH})$ and another sharp singlet around $\delta 0.2 \mathrm{ppm}$ to the ethynyl trimethylsilane.

The new 1,4-disubstituted $\alpha$-hydroxy-1,2,3-triazoles 9a-9r were obtained in good yields by the copper- catalyzed azide-alkyne cycloaddition (CuAAC) reaction (Scheme 2). Although the aryl azides can be prepared by different synthetic approaches, the diazotization reaction of aromatic amines is one of the most commonly used methods. Thus, the aryl-azides 15a-15e were prepared from commercial anilines 14a-14d by diazotization reaction with $\mathrm{NaNO}_{2}$ followed by substitution with sodium azide $\left(\mathrm{NaN}_{3}\right)$ in yields ranging from 60 to $94 \%$. In order to avoid a reactional step, aryl azide substituted by $\mathrm{OCH}_{3}$ or $\mathrm{F}$ in the position 4 or unsubstituted aryl azide were generated in situ by copper(II)-catalyzed conversion of aryl boron acids, also known as Cham-Lam coupling. ${ }^{21}$ In these cases, aryl boronic acids 16a-16c were used in presence of $\mathrm{NaN}_{3}$ in methanol at $55^{\circ} \mathrm{C}$ for $1-2 \mathrm{~h}$. The main advantage of this method is to avoid the isolation of aryl azides, which are sometimes unstable and photosensitive. ${ }^{22}$ Thus $\alpha$-hydroxy-

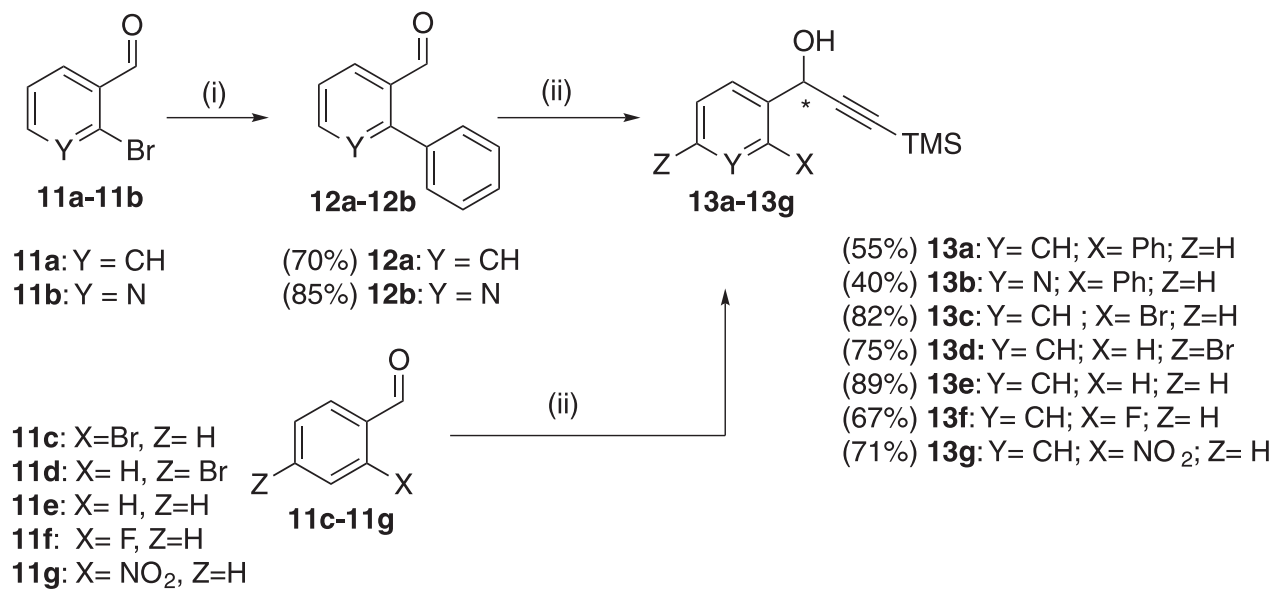

Scheme 1. Synthesis of propargyl alcohols 13a-13g. Reagents and conditions: (i) $10 \mathrm{~mol} \% \mathrm{Pd}(\mathrm{OAc})_{2}, 20 \mathrm{~mol} \% \mathrm{PPh}_{3}$, phenylboronic acid, $2 \mathrm{M} \mathrm{K}_{2} \mathrm{CO}_{3}$, toluene, $5 \mathrm{~h}, 100{ }^{\circ} \mathrm{C}$; (ii) ethynyl-trimethylsilane, $n$-BuLi, THF dry, $-5^{\circ} \mathrm{C}, 3 \mathrm{~h}$. 
1,2,3-triazole derivatives 9a-9r were prepared in one step by reaction of propargyl alcohols 13a-13g in the presence of sodium methoxide (NaOMe) as deprotection agent of the trimethylsilyl group (TMS) and sodium ascorbate as reduction agent. ${ }^{23}$ The presence of sodium ascorbate favors the in situ formation of $\mathrm{Cu}^{\mathrm{I}}$, avoiding the formation of agglomerates, and also avoids atmospheric oxygen interference, that may hinder the reaction process when directly using sources of copper(I). ${ }^{24}$ Compounds 9a-9r were characterized by ${ }^{1} \mathrm{H}$ and ${ }^{13} \mathrm{C}$ NMR. The ${ }^{1} \mathrm{H}$ NMR spectrum exhibited a sharp singlet signal in the region $\delta 7.7 \mathrm{ppm}$ confirming the presence of a triazole proton. Although compounds $\mathbf{9 f}, \mathbf{9 h}$ and $\mathbf{9 q}$ were obtained in low yields, there is not any relationship of these yields with the pattern of substitution of aryl azides or alkynes. As described in the literature, ${ }^{24}$ the reaction CuAAC is not significantly affected by the steric and electronic properties of the groups attached to the azide and alkyne centers.

Aiming the synthesis of benzo $[c]$ chromene-triazoles, the $\alpha$-hydroxy-1,2,3-triazoles (9p-9r) were submitted to cyclization conditions using the Pd-catalyzed $\beta$-carbon cleavage by the coordination of hydroxy group for obtaining $\mathrm{C}-\mathrm{O}$ bond ${ }^{25}$ However, instead of benzochromenes-triazoles 14a-14c, new $9 H$-fluorenes-1,2,3-triazoles 10a-10c were obtained with yields ranging from 25 to $40 \%$, by Friedel-Crafts alkylation (Scheme 3). Similar results have been reported in the literature ${ }^{26,27}$ using Lewis acid. The characterization of the $9 \mathrm{H}$-fluorenes-1,2,3-triazoles was performed by IR, ${ }^{1} \mathrm{H}$ and ${ }^{13} \mathrm{C}$ NMR. In the IR spectrum, the absence of the broadband in the $3300 \mathrm{~cm}^{-1}$ region referring to the stretching of the $\mathrm{O}-\mathrm{H}$ bond of alcohols occurs. The ${ }^{13} \mathrm{C}$ NMR spectrum exhibited signals in the region $\delta 45$ and $118 \mathrm{ppm}$, relative to the presence of benzyl and triazole $(\mathrm{CH})$.

\section{Biological evaluation}

The capacity of each compound to inhibit the glycine transporter GlyT1 was evaluated and a maximal concentration of ALX $5407(0.5 \mu \mathrm{M})$ was used as a positive control. At the high concentration tested $(10 \mu \mathrm{M})$, only the $\alpha$-hydroxy-1,2,3-triazole $\mathbf{9 b}$ presented a statistically significant effect (Table 1).

In order to determine the potency of $\mathbf{9 b}$, we performed a full concentration-response curve (Figure 3) and measured the mean inhibitory concentration $\left(\mathrm{IC}_{50}\right)$, i.e., the concentration inhibiting by $50 \%$ the specific transport

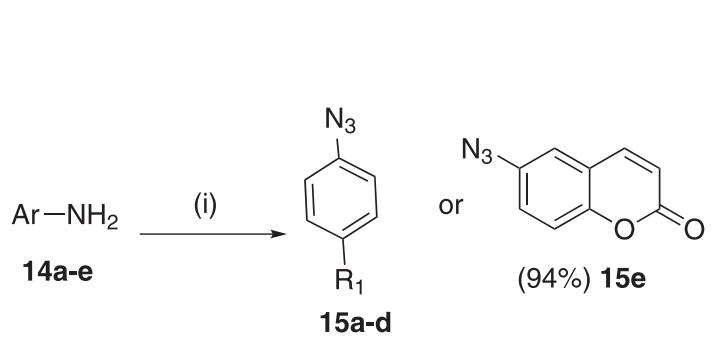

$(80 \%)$ 15a. $\mathrm{R}_{1}=\mathrm{COOH}$

(75\%) 15b. $\mathrm{R}_{1}=\mathrm{Br}$

$(60 \%) 15 c . R_{1}=$ COOMe

$(70 \%) 15 d . R_{1}=$ COMe

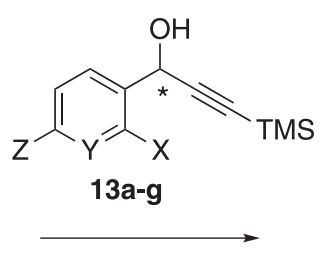

(ii)

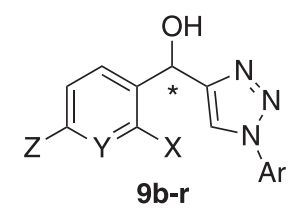

$(60 \%) 9 b . X=\mathrm{Br} ; \mathrm{Y}=\mathrm{CH} ; \mathrm{Z}=\mathrm{H} ; \mathrm{Ar}=4-\mathrm{PhBr}$ (45\%) 9c. $X=\mathrm{Br} ; \mathrm{Y}=\mathrm{CH} ; \mathrm{Z}=\mathrm{H} ; \mathrm{Ar}=4-\mathrm{PhCOOMe}$ (53\%) 9d. $X=\mathrm{Br} ; \mathrm{Y}=\mathrm{CH} ; \mathrm{Z}=\mathrm{H} ; \mathrm{Ar}=2 \mathrm{H}$-chromen-2-one (25\%) 9f. $X=\mathrm{Br} ; \mathrm{Y}=\mathrm{CH} ; \mathrm{Z}=\mathrm{H} ; \mathrm{Ar}=4-\mathrm{PhCOOH}$ (58\%) 9g. $X=F ; Y=C H ; Z=H ; A r=4-P h B r$ $(30 \%)$ 9h. $\mathrm{X}=\mathrm{NO}_{2} ; \mathrm{Y}=\mathrm{CH} ; \mathrm{Z}=\mathrm{H} ; \mathrm{Ar}=4-\mathrm{PhBr}$ (85\%) 9i. $\mathrm{X}=\mathrm{H} ; \mathrm{Y}=\mathrm{CH} ; \mathrm{Z}=\mathrm{Br} ; \mathrm{Ar}=4-\mathrm{PhBr}$ (65\%) 9j. $\mathrm{X}=\mathrm{H} ; \mathrm{Y}=\mathrm{CH} ; \mathrm{Z}=\mathrm{H} ; \mathrm{Ar}=4-\mathrm{PhBr}$ $(65 \%) 9 \mathrm{~m} . X=\mathrm{Ph} ; \mathrm{Y}=\mathrm{N} ; \mathrm{Z}=\mathrm{H} ; \mathrm{Ar}=4-\mathrm{PhCOOMe}$ (48\%) 9o. $\mathrm{X}=\mathrm{Ph} ; \mathrm{Y}=\mathrm{CH} ; \mathrm{Z}=\mathrm{H} ; \mathrm{Ar}=2 \mathrm{H}$-chromen-2-one (40\%) 9r: $X=P h ; Y=C H ; Z=H ; A r=4-P h C O M e$<smiles>[Y][Y]1c([Z])ccc(C(O)c2cn(-c3ccc([R])cc3)nn2)c1C(O)c1ccc(C)cc1</smiles>

(54\%) 9a. $X=B r ; Y=C H ; Z=H ; R_{2}=4-F$ $(60 \%) 9 e . X=B r ; Y=C H ; Z=H ; R_{2}=H$ (55\%) 9I. $X=H ; Y=C H ; Z=B r ; R_{2}=4-P h F$ $(70 \%) 9 n . X=P h ; Y=N ; Z=H ; R_{2}=4-F$ $\mathrm{R}_{2}(30 \%)$ 9q. $X=P h ; Y=C H ; Z=H ; R_{2}=4-O M e$ $(65 \%)$ 9p. $X=P h ; Y=C H ; Z=H ; R_{2}=4-F$

Scheme 2. Synthesis of $\alpha$-hydroxy-1,2,3-triazole derivatives (9a-9r). Reagents and conditions: (i) $\mathrm{H}_{2} \mathrm{SO}_{4}, \mathrm{H}_{2} \mathrm{O}, \mathrm{NaNO}_{2}, \mathrm{NaN}_{3}, 0{ }^{\circ} \mathrm{C}, 0.5-1$ h; (ii) 10 mol\% sodium ascorbate, $5 \mathrm{~mol} \% \mathrm{Cu}(\mathrm{OAc})_{2}, \mathrm{MeOH}, 1 \mathrm{M} \mathrm{NaOMe}, \mathrm{rt}, 20 \mathrm{~h}$; (iii) $10 \mathrm{~mol} \% \mathrm{Cu}(\mathrm{OAc})_{2}, \mathrm{NaN}_{3}, \mathrm{MeOH}, 55^{\circ} \mathrm{C}, 1-2 \mathrm{~h} ; 20 \mathrm{~mol} \%$ sodium ascorbate, $1 \mathrm{M} \mathrm{NaOMe}, \mathrm{rt}, 20 \mathrm{~h}$. 

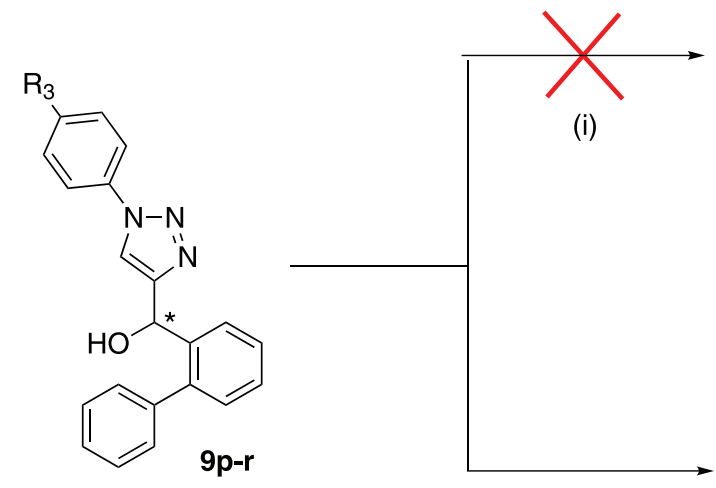

(i)

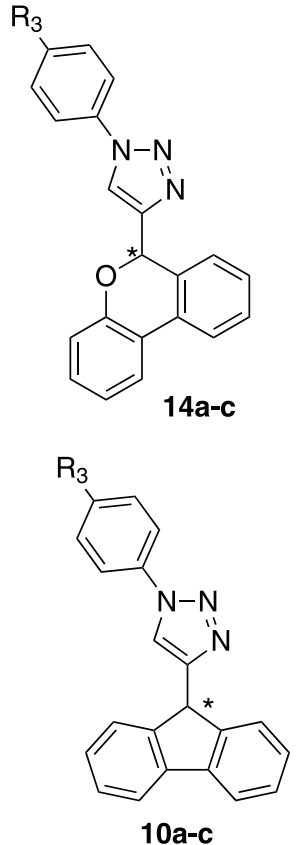

$(40 \%)$ 10a: $R_{3}=F$

$(30 \%)$ 10b: $\mathrm{R}_{3}=\mathrm{OMe}$

$(25 \%) 10 \mathrm{c}: \mathrm{R}_{3}=\mathrm{COMe}$

Scheme 3. Synthesis of $9 \mathrm{H}$-fluorenes-1,2,3-triazoles. Reagents and conditions: (i) $5 \mathrm{~mol} \% \mathrm{Pd}(\mathrm{OAc})_{2}, \mathrm{Na}_{2} \mathrm{CO}_{3}, \mathrm{PhI}(\mathrm{TFA})_{2}, \mathrm{DCE}, 100{ }^{\circ} \mathrm{C}, 36 \mathrm{~h}$.

Table 1. Effects of compounds on $\left[{ }^{3} \mathrm{H}\right]$-glycine uptake by HEK293 cells expressing GlyT1. Transport rates were measured as described in Experimental section. Endogenous glycine uptake by parental HEK cells was subtracted from every value. The uptake assays were performed in the presence of compounds $(10 \mu \mathrm{M})$ or ALX5407 $(0.5 \mu \mathrm{M})$ and compared to control. Data from this screening assay are means \pm S.E. from two independent experiments, each performed in duplicate

\begin{tabular}{lc}
\hline Compound & {$\left[{ }^{3} \mathrm{H}\right]$-glycine uptake / $(\%$ control $)$} \\
\hline ALX-5407 & $1.4 \pm 0.1$ \\
9a & $83.4 \pm 2.5$ \\
9b & $41.8 \pm 2.7$ \\
9c & $98.4 \pm 9.2$ \\
9d & $112.9 \pm 6.5$ \\
9e & $114.2 \pm 11.6$ \\
9f & $100.8 \pm 16.2$ \\
9g & $101.6 \pm 6.6$ \\
9h & $83.6 \pm 3.8$ \\
9i & $85.5 \pm 2.4$ \\
9j & $77.3 \pm 1.6$ \\
9l & $76.5 \pm 8.4$ \\
9m & $93.8 \pm 5.7$ \\
9n & $114.0 \pm 3.8$ \\
9o & $96.8 \pm 7.5$ \\
9p & $89.8 \pm 0.5$ \\
9q & $98.3 \pm 3.6$ \\
9r & $97.1 \pm 5.5$ \\
10a & $93.5 \pm 6.5$ \\
10b & $94.8 \pm 4.6$ \\
\hline
\end{tabular}

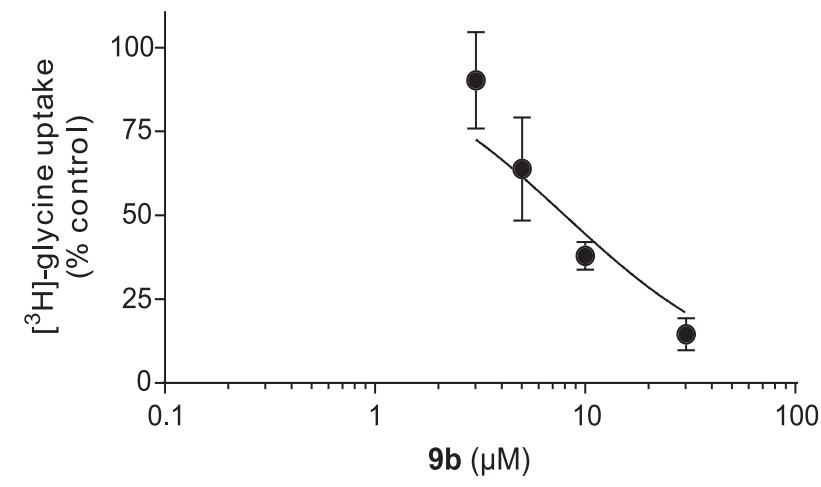

Figure 3. Concentration-response curve for inhibition of $\left[{ }^{3} \mathrm{H}\right]$-glycine uptake by HEK293 cells expressing GlyT1. Transport rates were measured as described in Experimental section. Data are means \pm S.E. from three independent experiments, each performed in duplicate. The curve was plotted using the parameters fitted by non-linear regression, fixing top and bottom to 100 and $0 \%$, respectively.

of glycine through GlyT1. The $\mathrm{IC}_{50}$ of $\mathbf{9 b}$ was $8.0 \mu \mathrm{M}$, indicating a relatively low potency as compared to different compounds reported in the literature ${ }^{9,15}$ that have $\mathrm{IC}_{50}$ values in the nanomolar range (see Introduction section and Table 1). As only compound $\mathbf{9 b}$ was active, we were not able to establish some structure-activity relationship. However, as $\mathbf{9 b}$ had some activity contrarily to $\mathbf{9 a}$, we can infer that the bromine plays an important role for the pharmacological activity.

\section{Conclusions}

In summary, we have synthesized novel $\alpha$-hydroxy1,2,3-triazoles under mild conditions in yields ranging 
from 25 to $85 \%$. The conditions of $\mathrm{Pd}$-catalyzed $\mathrm{C}-\mathrm{O}$ bond did not lead to the expected benzo[c]chromene-triazoles but to new $9 H$-fluorenes-1,2,3-triazoles by Friedel-Crafts alkylation reaction. All the synthesized compounds were evaluated as glycine transporter (GlyT1) inhibitors. As 9b was the only active compound with a relatively low potency $\left(\mathrm{IC}_{50}=8.0 \mu \mathrm{M}\right)$, we have to conclude that the $\alpha$-hydroxy1,2,3-triazole scaffold is not a good starting point for the discovery of new inhibitors of the GlyT1, a putative molecular target for the treatment of cognitive disorders.

\section{Experimental}

\section{General information}

For the structural elucidation of the synthesized compounds, ${ }^{1} \mathrm{H}$ and ${ }^{13} \mathrm{C}$ NMR spectra were recorded at ambient temperature on a Bruker Advance III spectrometer (operating at $400 \mathrm{MHz}$ for ${ }^{1} \mathrm{H} \mathrm{NMR}$ and $101 \mathrm{MHz}$ for ${ }^{13} \mathrm{C} \mathrm{NMR}$, with $\mathrm{CDCl}_{3}$ or dimethyl sulfoxide (DMSO- $d_{6}$ ) as solvent). The chemical shifts $(\delta)$ were given in parts per million (ppm) from internal tetramethylsilane on the $\delta$ scale, multiplicity ( $\mathrm{s}=$ singlet, $\mathrm{d}=$ doublet, $\mathrm{t}=$ triplet, $\mathrm{q}=$ quartet, $\mathrm{m}=$ multiplet $)$. All coupling constants ( $J$ values) were given in Hz. Melting points (mp) were determined with an electrothermal, analog model. Infrared spectra were performed using a Varian-3100 spectrometer with ATR (attenuated total reflection). High resolution mass spectra (HRMS) were obtained using a Bruker, MicrOTOF II instrument. Reactions were monitored by thin layer chromatography (TLC) using TLC silica gel 60 F254 (Merck, São Paulo, Brazil). Silica gel column chromatography was performed over Merck silica gel $60 \AA$ (particle size: 0.040-0.063 mm, 230-400 mesh ASTM). All reagents used were commercially obtained (Merck, São Paulo, Brazil and Oakwood Chemical, San Diego, CA, USA) and, where necessary, purified prior to use, such as tetrahydrofuran (THF), that was dried by metallic sodium.

\section{Synthesis of compounds $12 a-12 b$}

In a $10 \mathrm{~mL}$ round-bottomed flask, it was added 2-bromobenzaldehyde (2.16 mmol), phenylboronic acid (0.38 g, $3.11 \mathrm{mmol}), \mathrm{Pd}(\mathrm{OAc})_{2}(0.048 \mathrm{~g}, 0.216 \mathrm{mmol})$, triphenylphosphine $(0.11 \mathrm{~g}, 0.432 \mathrm{mmol})$, toluene $(6.5 \mathrm{~mL})$ and $\mathrm{K}_{2} \mathrm{CO}_{3}(0.28 \mathrm{~g}, 2.16 \mathrm{mmol})$. The reaction mixture was stirred for $5 \mathrm{~h}$ at $100{ }^{\circ} \mathrm{C}$ under $\mathrm{N}_{2}$ atmosphere. At the end of the reaction toluene was evaporated under reduced pressure and the mixture was extracted with EtOAc $(2 \times 20 \mathrm{~mL})$, washed with brine $(20 \mathrm{~mL})$, dried $\left(\mathrm{Na}_{2} \mathrm{SO}_{4}\right)$ and filtered.
The solvent was evaporated under reduced pressure and the residue was purified by flash chromatography using ethyl acetate/hexane (5:95) as eluent.

\section{[1,1'-Biphenyl]-2-carbaldehyde (12a)}

Yield 70\%; colorless oil; ${ }^{1} \mathrm{H}$ NMR $\left(400 \mathrm{MHz}, \mathrm{CDCl}_{3}\right)$ $\delta 9.99(\mathrm{~s}, 1 \mathrm{H}), 8.04(\mathrm{dd}, J 7.8,1.3 \mathrm{~Hz}, 1 \mathrm{H}), 7.65(\mathrm{td}, J 7.5$, $1.4 \mathrm{~Hz}, 1 \mathrm{H}), 7.54-7.44$ (m, 5H), 7.41-7.37 (m, 2H).

\section{2-Phenylnicotinaldehyde (12b)}

Yield 85\%; brown oil; ${ }^{1} \mathrm{H}$ NMR (400 $\mathrm{MHz}, \mathrm{CDCl}_{3}$ ) $\delta 10.06(\mathrm{~d}, J 0.8 \mathrm{~Hz}, 1 \mathrm{H}), 8.89(\mathrm{dd}, J 4.7,1.8 \mathrm{~Hz}, 1 \mathrm{H})$, 8.31 (dd, J 7.9, $1.8 \mathrm{~Hz}, 1 \mathrm{H}), 7.62-7.57$ (m, 2H), 7.55-7.51 (m, 3H), 7.45 (ddd, J 7.9, 4.7, $0.8 \mathrm{~Hz}, 1 \mathrm{H})$.

\section{Synthesis of propargyl alcohols 13a-13g}

The products $\mathbf{1 3 a} \mathbf{a} \mathbf{1 3 g}$ were prepared following the procedure of Wienhold et al. ${ }^{28} n$-BuLi (2.5 $\mathrm{M}$ in hexane, $2.8 \mathrm{~mL}, 7.0 \mathrm{mmol}$ ) was added to a stirred solution of (trimethylsilyl)acetylene $(0.99 \mathrm{~mL}, 7.02 \mathrm{mmol})$ in anhydrous THF $(7 \mathrm{~mL})$ at $-5{ }^{\circ} \mathrm{C}$ under an $\mathrm{N}_{2}$ atmosphere. After $15 \mathrm{~min}$, benzaldehyde $(5.4 \mathrm{mmol})$ was added and the reaction mixture was stirred for $3 \mathrm{~h}$ at $0{ }^{\circ} \mathrm{C}$. The reaction was quenched with saturated aqueous $\mathrm{NaHCO}_{3}(10 \mathrm{~mL})$ and the layers were separated. The aqueous phase was extracted with $\mathrm{Et}_{2} \mathrm{O}(2 \times 10 \mathrm{~mL})$ and washed with brine (5 mL). The combined organic layers were dried over $\mathrm{Na}_{2} \mathrm{CO}_{3}$, filtered, and evaporated to dryness under reduced pressure. When necessary the products were purified by flash chromatography using ethyl acetate/hexane (10:90) as eluent.

1-([1,1'-Biphenyl]-2-yl)-3-(trimethylsilyl)prop-2-yn-1-ol (13a) Yield 55\%; colorless oil; IR (KBr) $v_{\max } / \mathrm{cm}^{-1} 3349$ (OH), $2173(\mathrm{C} \equiv \mathrm{C}) ;{ }^{1} \mathrm{H}$ NMR (400 MHz, $\mathrm{CDCl}_{3}$ ) $\delta 7.89$ (dd, J 7.7, 1.3 Hz, 1H), 7.48-7.39 (m, 7H), 7.31 (dd, J 7.5, $1.3 \mathrm{~Hz}, 1 \mathrm{H}), 5.47$ (s, 1H), 0.20 (s, 9H).

1-(2-Phenylpyridin-3-yl)-3-(trimethylsilyl)prop-2-yn-1-ol (13b)

Yield $40 \%$; pale yellow solid; mp $126-127^{\circ} \mathrm{C}$; IR (KBr) $\mathrm{v}_{\max } / \mathrm{cm}^{-1} 3201(\mathrm{OH}), 2174(\mathrm{C} \equiv \mathrm{C}) ;{ }^{1} \mathrm{H} \mathrm{NMR}(400 \mathrm{MHz}$, $\left.\mathrm{CDCl}_{3}\right) \delta 8.69(\mathrm{dd}, J 4.7,1.7 \mathrm{~Hz}, 1 \mathrm{H}), 8.21(\mathrm{dd}, J$ 7.9, $1.7 \mathrm{~Hz}, 1 \mathrm{H}), 7.67-7.62$ (m, 2H), 7.52-7.45 (m, 3H), 7.39 (dd, J 7.9, $4.7 \mathrm{~Hz}, 1 \mathrm{H}), 5.54$ (d, J $4.4 \mathrm{~Hz}, 1 \mathrm{H}), 0.20$ (s, J $3.5 \mathrm{~Hz}, 9 \mathrm{H})$.

1-(2-Bromophenyl)-3-(trimethylsilyl)prop-2-yn-1-ol (13c)

Yield 80\%; yellow oil; IR (KBr) $v_{\max } / \mathrm{cm}^{-1} 3340(\mathrm{OH})$, $2172(\mathrm{C} \equiv \mathrm{C}) ;{ }^{1} \mathrm{H}$ NMR $\left(400 \mathrm{MHz}, \mathrm{CDCl}_{3}\right) \delta 7.80$ (dd, J 7.7, 
$1.7 \mathrm{~Hz}, 1 \mathrm{H}), 7.59$ (dd, $J$ 8.0, $1.2 \mathrm{~Hz}, 1 \mathrm{H}), 7.39$ (td, $J$ 7.6, $1.1 \mathrm{~Hz}, 1 \mathrm{H}), 7.22(\mathrm{td}, J 7.7,1.7 \mathrm{~Hz}, 1 \mathrm{H}), 5.81(\mathrm{~s}, 1 \mathrm{H}), 2.53$ (s, 1H), 0.23 (s, J $3.5 \mathrm{~Hz}, 9 \mathrm{H})$.

1-(4-Bromophenyl)-3-(trimethylsilyl)prop-2-yn-1-ol (13d)

Yield 75\%; colorless oil; IR (KBr) $v_{\max } / \mathrm{cm}^{-1} 3342$ (OH), $2174(\mathrm{C} \equiv \mathrm{C}) ;{ }^{1} \mathrm{H}$ NMR (400 MHz, $\left.\mathrm{CDCl}_{3}\right) \delta 7.51$ $(\mathrm{d}, J 8.5 \mathrm{~Hz}, 2 \mathrm{H}), 7.41(\mathrm{~d}, J 8.5 \mathrm{~Hz}, 2 \mathrm{H}), 5.41(\mathrm{~s}, 1 \mathrm{H}), 0.20$ (s, $J 3.5 \mathrm{~Hz}, 9 \mathrm{H}$ ).

1-Phenyl-3-(trimethylsilyl)prop-2-yn-1-ol (13e)

Yield 90\%; yellow light oil; IR (KBr) $v_{\max } / \mathrm{cm}^{-1} 3343$ (OH), $2173(\mathrm{C} \equiv \mathrm{C}) ;{ }^{1} \mathrm{H}$ NMR $\left(400 \mathrm{MHz}, \mathrm{CDCl}_{3}\right) \delta$ 7.57-7.53 $(\mathrm{m}, 1 \mathrm{H}), 7.41-7.33(\mathrm{~m}, 3 \mathrm{H}), 5.46(\mathrm{~d}, J 5.8 \mathrm{~Hz}, 1 \mathrm{H}), 0.21$ (s, 9H).

1-(2-Fluorophenyl)-3-(trimethylsilyl)prop-2-yn-1-ol (13f)

Yield 67\%; colorless oil; IR (KBr) $v_{\max } / \mathrm{cm}^{-1} 3343$ $(\mathrm{OH}), 2173(\mathrm{C} \equiv \mathrm{C}) ;{ }^{1} \mathrm{H}$ NMR $\left(400 \mathrm{MHz}, \mathrm{CDCl}_{3}\right) \delta 7.65$ $(\mathrm{td}, J 7.6,1.8 \mathrm{~Hz}, 1 \mathrm{H}), 7.34-7.26(\mathrm{~m}, 1 \mathrm{H}), 7.16(\mathrm{td}, J$ 7.6, $1.0 \mathrm{~Hz}, 1 \mathrm{H}), 7.08-7.01(\mathrm{~m}, 1 \mathrm{H}), 5.72(\mathrm{~s}, 1 \mathrm{H}), 0.19(\mathrm{~s}, 9 \mathrm{H})$.

1-(2-Nitrophenyl)-3-(trimethylsilyl)prop-2-yn-1-ol (13g)

Yield 71\%; brown oil; IR (KBr) $v_{\max } / \mathrm{cm}^{-1} 3389(\mathrm{OH})$, $2175(\mathrm{C} \equiv \mathrm{C}) ;{ }^{1} \mathrm{H}$ NMR $\left(400 \mathrm{MHz}, \mathrm{CDCl}_{3}\right) \delta 7.94(\mathrm{td}, J 7.9$, $1.3 \mathrm{~Hz}, 2 \mathrm{H}), 7.67$ (td, J 7.6, $1.3 \mathrm{~Hz}, 1 \mathrm{H}), 7.51$ (td, J 7.9, $1.4 \mathrm{~Hz}, 1 \mathrm{H}), 5.97$ (s, 1H), 0.19 (s, 9H).

\section{Preparation of aryl azides $15 a-15 e$}

The aryl azides 15a-15e were prepared following the procedure of Wilkening et al. ${ }^{29}$ The aniline derivative (7.5 mmol) was dissolved in $5 \mathrm{~mL}$ of water and concentrated sulfuric acid $(98 \%, 1.5 \mathrm{~mL})$ and additional water $(1.5 \mathrm{~mL})$ was added. The suspension was cooled to $0{ }^{\circ} \mathrm{C}$ and a solution of $\mathrm{NaNO}_{2}(0.5 \mathrm{~g}, 7.6 \mathrm{mmol})$ in water $(1.5 \mathrm{~mL})$ was slowly added under constant stirring. After $15 \mathrm{~min}$, $\mathrm{NaN}_{3}$ (0.6 g, $9.3 \mathrm{mmol}$ ) was added and the mixture was stirred for additional 0.5-1 h. The reaction mixture was extracted with ethyl acetate $(3 \times 20 \mathrm{~mL})$ and the combined organic fractions were washed with water $(50 \mathrm{~mL})$. The organic layer was dried over $\mathrm{Na}_{2} \mathrm{SO}_{4}$ and concentrated under reduced pressure. The desired azides 15a-15e were obtained without further purification.

\section{4-Azidobenzoic acid (15a)}

Yield 80\%; pale yellow solid; mp $185{ }^{\circ} \mathrm{C}$; IR $(\mathrm{KBr})$ $v_{\max } / \mathrm{cm}^{-1} 2105(\mathrm{~N} \equiv \mathrm{N}), 1284(\mathrm{C}-\mathrm{O}) ;{ }^{1} \mathrm{H} \mathrm{NMR}(400 \mathrm{MHz}$, DMSO- $\left.d_{6}\right) \delta 12.98(\mathrm{~s}, 1 \mathrm{H}, \mathrm{OH}), 8.54-7.70(\mathrm{~m}, 2 \mathrm{H}, \mathrm{CH})$, 7.58-6.88 (m, 2H, CH).

\section{1-Azido-4-bromobenzene (15b)}

Yield 85\%; brown liquid; IR (KBr) $v_{\max } / \mathrm{cm}^{-1} 2114$ $(\mathrm{N} \equiv \mathrm{N}) ;{ }^{1} \mathrm{H}$ NMR $\left(400 \mathrm{MHz}, \mathrm{CDCl}_{3}\right) \delta 7.48(\mathrm{~d}, J 8.8 \mathrm{~Hz}$, 2H, Ar-H), 6.93 (d, J $8.8 \mathrm{~Hz}, 2 \mathrm{H}, \mathrm{Ar}-\mathrm{H})$.

\section{Methyl 4-azidobenzoate (15c)}

Yield 70\%; white solid; mp 118-119 ${ }^{\circ} \mathrm{C}$; IR ( $\left.\mathrm{KBr}\right)$ $v_{\max } / \mathrm{cm}^{-1} 2113(\mathrm{~N} \equiv \mathrm{N}), 1716(\mathrm{C}=\mathrm{O}) ;{ }^{1} \mathrm{H} \mathrm{NMR}(400 \mathrm{MHz}$, $\left.\mathrm{CDCl}_{3}\right) \delta 8.03(\mathrm{~d}, J 8.8 \mathrm{~Hz}, 1 \mathrm{H}), 7.07(\mathrm{~d}, J 8.8 \mathrm{~Hz}, 1 \mathrm{H})$, $3.91(\mathrm{~s}, 1 \mathrm{H})$.

\section{1-(4-Azidophenyl)ethanone (15d)}

Yield 70\%; orange solid; mp $118-119{ }^{\circ} \mathrm{C}$; IR (KBr) $v_{\max } / \mathrm{cm}^{-1} 2091(\mathrm{~N} \equiv \mathrm{N}), 1668(\mathrm{C}=\mathrm{O}) ;{ }^{1} \mathrm{H} \mathrm{NMR}(400 \mathrm{MHz}$, $\left.\mathrm{CDCl}_{3}\right) \delta 7.96(\mathrm{~d}, J 8.7 \mathrm{~Hz}, 2 \mathrm{H}), 7.09(\mathrm{~d}, J 8.7 \mathrm{~Hz}, 1 \mathrm{H})$, $2.58(\mathrm{~s}, 1 \mathrm{H})$.

\section{6-Azido-2H-chromen-2-one (15e)}

Yield 94\%; orange solid; mp 159-161 ${ }^{\circ} \mathrm{C}$; IR (KBr) $v_{\max } / \mathrm{cm}^{-1} 2105(\mathrm{~N} \equiv \mathrm{N}), 1711(\mathrm{C}=\mathrm{O}) ;{ }^{1} \mathrm{H}$ NMR $(400 \mathrm{MHz}$, $\left.\mathrm{CDCl}_{3}\right) \delta 7.66(\mathrm{~d}, J 9.6 \mathrm{~Hz}, 1 \mathrm{H},=\mathrm{CH}), 7.34(\mathrm{~d}, J 8.8 \mathrm{~Hz}$, $1 \mathrm{H}, \mathrm{Ar}-\mathrm{H}), 7.20$ (dd, J 8.8, $2.6 \mathrm{~Hz}, 1 \mathrm{H}, \mathrm{Ar}-\mathrm{H}), 7.12$ (d, $J 2.6 \mathrm{~Hz}, 1 \mathrm{H}, \mathrm{Ar}-\mathrm{H}), 6.48(\mathrm{~d}, J 9.6 \mathrm{~Hz}, 1 \mathrm{H},=\mathrm{CH})$.

\section{Synthesis of $\alpha$-hydroxy-1,2,3-triazoles $9 a-9 r$}

The triazoles were prepared following the procedure of Oikawa et al. ${ }^{23}$

\section{Procedure A}

In a $25 \mathrm{~mL}$ round-bottomed flask, aryl azide was prepared using arylboronic acid $(0.5 \mathrm{mmol}), \mathrm{NaN}_{3}$ (0.75 mmol), $\mathrm{Cu}(\mathrm{OAc})_{2}(0.05 \mathrm{mmol})$ and $\mathrm{MeOH}(3 \mathrm{~mL})$. Then, the mixture was stirred at $55^{\circ} \mathrm{C}$ for $1.5 \mathrm{~h}$ under aerobic condition. After cooling to room temperature, sodium ascorbate $(0.1 \mathrm{mmol}), \mathrm{NaOMe}(1 \mathrm{M}, 0.5 \mathrm{mmol})$ and alkyne $(0.5 \mathrm{mmol})$ were added to the resultant mixture, which was stirred at room temperature for $24 \mathrm{~h}$ under $\mathrm{N}_{2}$ atmosphere. At the end of the reaction, the solution was bubbled with air at ambient temperature for $1 \mathrm{~h}$ to oxidize the residual organoboron compound. The mixture was extracted with EtOAc $(3 \times 10 \mathrm{~mL})$, washed with brine $(20 \mathrm{~mL})$, dried $\left(\mathrm{Na}_{2} \mathrm{SO}_{4}\right)$, and filtered. The solvent was evaporated under reduced pressure and the residue was purified by flash chromatography using ethyl acetate/ hexane (30:70) as eluent. The solvents used to perform TLC plate analysis were ethyl acetate/hexane (40:60).

\section{Procedure B}

In a $10 \mathrm{~mL}$ round-bottomed flask, it was added aryl azide $(0.5 \mathrm{mmol}), \mathrm{Cu}(\mathrm{OAc})_{2}(0.025 \mathrm{mmol})$, sodium ascorbate 
(0.05 mmol), alkyne (0.5 mmol), $\mathrm{MeOH}(3 \mathrm{~mL})$ and $\mathrm{NaOMe}(1 \mathrm{M}, 0.5 \mathrm{mmol})$. The reaction mixture was stirred at room temperature for $24 \mathrm{~h}$. At the end of the reaction, the mixture was extracted with EtOAc $(3 \times 10 \mathrm{~mL})$, washed with brine $(20 \mathrm{~mL})$, dried $\left(\mathrm{Na}_{2} \mathrm{SO}_{4}\right)$, and filtered. The solvent was evaporated under reduced pressure and the residue was purified by flash chromatography using ethyl acetate/hexane (30:70) as eluent.

(2-Bromophenyl)(1-(4-fluorophenyl)-1H-1,2,3-triazol-4-yl) methanol (9a)

Procedure A: the product (9a) was purified by flash chromatography using ethyl acetate/hexane (30:70) as eluent to give a white solid in $54 \%$ yield. mp $102-104{ }^{\circ} \mathrm{C}$; ${ }^{1} \mathrm{H} \mathrm{NMR}\left(400 \mathrm{MHz}, \mathrm{CDCl}_{3}\right) \delta$ 7.79-7.73 (m, 1H), 7.68-7.60 (m, 3H), 7.59-7.54 (m, 1H), 7.40 (t, J7.5 Hz, 1H), 7.23-7.14 $(\mathrm{m}, 3 \mathrm{H}), 6.44(\mathrm{~s}, 1 \mathrm{H}) ;{ }^{13} \mathrm{C}$ NMR $\left(101 \mathrm{MHz}, \mathrm{CDCl}_{3}\right)$ $\delta 163.77,161.23,150.52,140.69,133.18,132.84,129.56$, $128.25,127.98,122.68,122.59,122.21,120.11,116.79$, 116.56, 67.76; HRMS(electrospray ionization (ESI)) $\mathrm{m} / \mathrm{z}$, calcd. for $\mathrm{C}_{15} \mathrm{H}_{11} \mathrm{BrFN}_{3} \mathrm{O}+\mathrm{Na}[\mathrm{M}+\mathrm{Na}]^{+}: 369.9967$, found: 369.9964.

(2-Bromophenyl)(1-(4-bromophenyl)-1H-1,2,3-triazol-4-yl) methanol (9b)

Procedure B: the product $(\mathbf{9 b})$ was purified by flash chromatography using ethyl acetate/hexane (30:70) as eluent to give a white solid in $65 \%$. mp $160-161{ }^{\circ} \mathrm{C}$; ${ }^{1} \mathrm{H}$ NMR $\left(400 \mathrm{MHz}\right.$, DMSO- $\left.d_{6}\right) \delta 8.67(\mathrm{~s}, 1 \mathrm{H}), 7.89(\mathrm{~d}$, $J 8.9 \mathrm{~Hz}, 2 \mathrm{H}), 7.81-7.73(\mathrm{~m}, 3 \mathrm{H}), 7.59(\mathrm{~d}, J 8.7 \mathrm{~Hz}, 1 \mathrm{H})$, $7.46(\mathrm{t}, J 7.5 \mathrm{~Hz}, 1 \mathrm{H}), 7.26(\mathrm{t}, J 7.6 \mathrm{~Hz}, 1 \mathrm{H}), 6.31(\mathrm{~d}$, $J 4.8 \mathrm{~Hz}, 1 \mathrm{H}), 6.15(\mathrm{~d}, J 4.7 \mathrm{~Hz}, 1 \mathrm{H}) ;{ }^{13} \mathrm{C} \mathrm{NMR}(101 \mathrm{MHz}$, DMSO- $\left.d_{6}\right) \delta 151.49,142.63,136.29,133.18,132.71$, 129.82, 129.32, 128.33, 122.34, 122.19, 121.61, 121.42, 67.22; HRMS(ESI) $m / z$, calcd. for $\mathrm{C}_{15} \mathrm{H}_{11} \mathrm{Br}_{2} \mathrm{~N}_{3} \mathrm{O}+\mathrm{Na}$ $[\mathrm{M}+\mathrm{Na}]^{+}:$429.9269, found: 429.9161 .

Methyl 4-(4-((2-bromophenyl)(hydroxy)methyl)1H-1,2,3-triazol-1-yl)benzoate (9c)

Procedure B: the product $(\mathbf{9 c})$ was purified by flash chromatography using ethyl acetate/hexane (20:80 to 40:60) as eluent to give a white solid in $45 \%$ yield. mp 135-136 ${ }^{\circ} \mathrm{C}$; ${ }^{1} \mathrm{H}$ NMR $\left(400 \mathrm{MHz}, \mathrm{CDCl}_{3}\right) \delta 8.18(\mathrm{~d}$, $J 8.8 \mathrm{~Hz}, 2 \mathrm{H}), 7.80(\mathrm{~d}, J 8.8 \mathrm{~Hz}, 2 \mathrm{H}), 7.76(\mathrm{~s}, 1 \mathrm{H}), 7.72(\mathrm{dd}$, $J 7.8,1.6 \mathrm{~Hz}, 1 \mathrm{H}), 7.59(\mathrm{dd}, J 8.0,1.1 \mathrm{~Hz}, 1 \mathrm{H}), 7.41(\mathrm{td}$, $J 7.7,1.1 \mathrm{~Hz}, 1 \mathrm{H}), 7.25-7.20(\mathrm{~m}, 1 \mathrm{H}), 6.45(\mathrm{~d}, J 3.5 \mathrm{~Hz}, 1 \mathrm{H})$, $3.95(\mathrm{~s}, 3 \mathrm{H}), 3.21$ (d, J $3.9 \mathrm{~Hz}, 1 \mathrm{H}) ;{ }^{13} \mathrm{C}$ NMR $(101 \mathrm{MHz}$, $\left.\mathrm{CDCl}_{3}\right) \delta 165.89,150.82,140.67,139.93,132.87,131.28$, $130.28,129.63,128.26,128.00,122.25,119.96,119.75$, $67.74,52.48$.
6-(4-((2-Bromophenyl)(hydroxy)methyl)-1H-1,2,3-triazol1-yl)-2H-chromen-2-one (9d)

Procedure B: the product (9d) was purified by flash chromatography using ethyl acetate/hexane (50:50) as eluent to give a yellow pale solid in 53\% yield. mp 75-76 ${ }^{\circ} \mathrm{C}$; ${ }^{1} \mathrm{H}$ NMR $\left(400 \mathrm{MHz}, \mathrm{CDCl}_{3}\right) \delta 7.91$ (d, $J 2.5 \mathrm{~Hz}, 1 \mathrm{H}), 7.84(\mathrm{dd}, J 8.9,2.5 \mathrm{~Hz}, 1 \mathrm{H}), 7.80-7.73$ (m, $3 \mathrm{H}), 7.61(\mathrm{~d}, J 8.5 \mathrm{~Hz}, 1 \mathrm{H}), 7.49(\mathrm{~d}, J 8.9 \mathrm{~Hz}, 1 \mathrm{H}), 7.44(\mathrm{t}$, $J 7.2 \mathrm{~Hz}, 1 \mathrm{H}), 7.28-7.23(\mathrm{~m}, 1 \mathrm{H}), 6.57(\mathrm{~d}, J 9.6 \mathrm{~Hz}, 1 \mathrm{H})$, $6.48(\mathrm{~s}, 1 \mathrm{H}) ;{ }^{13} \mathrm{C} \mathrm{NMR}\left(101 \mathrm{MHz}, \mathrm{CDCl}_{3}\right) \delta 159.72,153.60$, $142.39,140.64,133.24,132.90,129.68,128.23,128.03$, 123.72, 122.22, 119.59, 119.54, 118.48, 118.35, 67.86 .

(2-Bromophenyl)(1-phenyl-1H-1,2,3-triazol-4-yl)methanol (9e)

Procedure A: the product $(\mathbf{9 e})$ was purified by flash chromatography using ethyl acetate/hexane (20:80) as eluent to give a yellow solid in $60 \%$ yield. mp $113-115^{\circ} \mathrm{C}$; ${ }^{1} \mathrm{H}$ NMR $\left(400 \mathrm{MHz}, \mathrm{CDCl}_{3}\right) \delta 7.76(\mathrm{~d}, J 7.3 \mathrm{~Hz}, 1 \mathrm{H}), 7.68$ (d, $J 7.8 \mathrm{~Hz}, 3 \mathrm{H}), 7.57$ (d, J 8.8 Hz, 1H), 7.49 (t, $J 7.6 \mathrm{~Hz}$, 2H), 7.41 (dd, $J 13.2,7.0 \mathrm{~Hz}, 2 \mathrm{H}), 7.21(\mathrm{t}, J 7.6 \mathrm{~Hz}, 1 \mathrm{H})$, 6.46 (s, 1H), 3.69 (s, 1H); ${ }^{13} \mathrm{C}$ NMR (101 MHz, $\left.\mathrm{CDCl}_{3}\right)$ $\delta 139.80,135.95,131.83,128.69,128.53,127.83,127.25$, 126.94, 121.22, 119.62, 66.94 .

4-(4-((2-Bromophenyl)(hydroxy)methyl)-1H-1,2,3-triazol1-yl)benzoic acid (9f)

Procedure B: the product (9f) was purified by flash chromatography using ethyl acetate/hexane (30:70) as eluent to give a white solid in $25 \%$ yield. ${ }^{1} \mathrm{H}$ NMR $\left(400 \mathrm{MHz}, \mathrm{DMSO}-d_{6}\right) \delta 8.74(\mathrm{~s}, 1 \mathrm{H}), 8.10(\mathrm{~d}, J 8.7 \mathrm{~Hz}$, 2H), 8.05 (d, J 8.3 Hz, 2H), 7.76 (d, J 7.7 Hz, 1H), 7.59 (d, $J 7.9 \mathrm{~Hz}, 1 \mathrm{H}), 7.46(\mathrm{t}, J 7.5 \mathrm{~Hz}, 1 \mathrm{H}), 7.26(\mathrm{t}, J 7.6 \mathrm{~Hz}, 1 \mathrm{H})$, $6.17(\mathrm{~s}, 1 \mathrm{H}) ;{ }^{13} \mathrm{C}$ NMR $\left(101 \mathrm{MHz}, \mathrm{DMSO}-d_{6}\right) \delta 151.61$, $142.60,139.82,132.72,131.48,129.83,129.33,128.34$, $122.20,121.52,120.09,67.22$.

(1-(4-Bromophenyl)-1H-1,2,3-triazol-4-yl)(2-fluorophenyl) methanol $(9 \mathrm{~g})$

Procedure B: the product $(\mathbf{9 g})$ was purified by flash chromatography using ethyl acetate/hexane (30:70) as eluent to give a white solid in $58 \%$ yield. $\mathrm{mp} 148-150{ }^{\circ} \mathrm{C}$; ${ }^{1} \mathrm{H}$ NMR $\left(400 \mathrm{MHz}, \mathrm{CDCl}_{3}\right) \delta 7.76(\mathrm{~s}, 1 \mathrm{H}), 7.65-7.61$ (m, 3H), 7.59 (d, J 9.0 Hz, 2H), 7.37-7.29 (m, 1H), 7.21 $(\mathrm{td}, J$ 7.6, 1.0 Hz, 1H), 7.11-7.05 (m, 1H), $6.37(\mathrm{~s}, 1 \mathrm{H})$; ${ }^{13} \mathrm{C}$ NMR (101 MHz, $\left.\mathrm{CDCl}_{3}\right) \delta 161.11,158.66,135.91$, $132.89,129.85,129.77,127.99,127.96,124.61,124.57$, $122.54,121.99,115.66,115.45,63.41$; HRMS(ESI) $\mathrm{m} / z$, calcd. for $\mathrm{C}_{15} \mathrm{H}_{11} \mathrm{BrFN}_{3} \mathrm{O}+\mathrm{Na}[\mathrm{M}+\mathrm{Na}]^{+}: 369.9967$, found: 369.9964. 
(1-(4-Bromophenyl)-1H-1,2,3-triazol-4-yl)(2-nitrophenyl) methanol $(9 h)$

Procedure B: the product (9h) was isolated by filtration and purified on a celite column to give a white solid in $30 \%$ yield. mp 190-191 ${ }^{\circ} \mathrm{C} ;{ }^{1} \mathrm{H}$ NMR (400 MHz, DMSO- $d_{6}$ ) $\delta 8.70$ (s, 1H), 7.98 (ddd, $J$ 7.7, 6.6, $1.2 \mathrm{~Hz}, 2 \mathrm{H}), 7.87$ (d, $J 9.0 \mathrm{~Hz}, 2 \mathrm{H}), 7.81(\mathrm{dd}, J 7.5,1.2 \mathrm{~Hz}, 1 \mathrm{H}), 7.77(\mathrm{~d}$, $J 9.0 \mathrm{~Hz}, 2 \mathrm{H}$ ), 7.58 (ddd, $J$ 8.2, 7.5, $1.4 \mathrm{~Hz}, 1 \mathrm{H}$ ), 6.49 (s, $1 \mathrm{H}) ;{ }^{13} \mathrm{C}$ NMR $\left(101 \mathrm{MHz}, \mathrm{DMSO}-d_{6}\right) \delta 151.22,148.09$, $138.15,136.25,134.01,133.13,129.25,129.14,124.65$, $122.35,121.68,121.42,63.69$.

(4-Bromophenyl)(1-(4-bromophenyl)-1 H-1,2,3-triazol-4-yl) methanol (9i)

Procedure B: the product (9i) was purified by flash chromatography using ethyl acetate/hexane (30:70) as eluent to give a white solid in $85 \%$ yield. $\mathrm{mp} 153-155^{\circ} \mathrm{C}$; ${ }^{1} \mathrm{H}$ NMR (400 MHz, DMSO- $\left.d_{6}\right) \delta 8.68(\mathrm{~s}, 1 \mathrm{H}), 7.88(\mathrm{~d}$, $J 8.9 \mathrm{~Hz}, 2 \mathrm{H}), 7.76(\mathrm{~d}, J 8.9 \mathrm{~Hz}, 2 \mathrm{H}), 7.54(\mathrm{~d}, J 8.5 \mathrm{~Hz}$, $2 \mathrm{H}), 7.42(\mathrm{~d}, J 8.4 \mathrm{~Hz}, 2 \mathrm{H}), 6.25(\mathrm{~d}, J 4.6 \mathrm{~Hz}, 1 \mathrm{H})$, $5.90(\mathrm{~d}, J 4.5 \mathrm{~Hz}, 1 \mathrm{H}) ;{ }^{13} \mathrm{C}$ NMR $\left(101 \mathrm{MHz}\right.$, DMSO- $\left.d_{6}\right)$ $\delta 152.85,143.47,136.30,133.19,131.50,129.20,122.36$, 121.63, 120.87, 120.74, 67.66; HRMS(ESI) $\mathrm{m} / \mathrm{z}$, calcd. for $\mathrm{C}_{15} \mathrm{H}_{11} \mathrm{Br}_{2} \mathrm{~N}_{3} \mathrm{O}+\mathrm{Na}[\mathrm{M}+\mathrm{Na}]^{+}:$429.9269, found: 429.9161.

(1-(4-Bromophenyl)-1H-1,2,3-triazol-4-yl)(phenyl)methanol (9j)

Procedure B: the product $(\mathbf{9} \mathbf{j})$ was purified by flash chromatography using ethyl acetate/hexane (30:70) as eluent to give a white solid in $60 \%$ yield. $\mathrm{mp} 155-156^{\circ} \mathrm{C}$; ${ }^{1} \mathrm{H}$ NMR $\left(400 \mathrm{MHz}, \mathrm{CDCl}_{3}\right) \delta 7.69(\mathrm{~s}, 1 \mathrm{H}), 7.63(\mathrm{~d}$, $J 9.0 \mathrm{~Hz}, 2 \mathrm{H}), 7.58(\mathrm{~d}, J 9.0 \mathrm{~Hz}, 2 \mathrm{H}), 7.51(\mathrm{~d}, J 7.1 \mathrm{~Hz}$, 1H), $7.40(\mathrm{t}, J 7.3 \mathrm{~Hz}, 1 \mathrm{H}), 7.34(\mathrm{t}, J 7.2 \mathrm{~Hz}, 1 \mathrm{H}), 6.12$ (s, $1 \mathrm{H}) ;{ }^{13} \mathrm{C}$ NMR $\left(101 \mathrm{MHz}, \mathrm{CDCl}_{3}\right) \delta 141.64,135.94$, 132.88, 128.74, 128.23, 126.43, 122.40, 121.92, 69.17; HRMS(ESI) $m / z$, calcd. for $\mathrm{C}_{15} \mathrm{H}_{12} \mathrm{BrN}_{3} \mathrm{O}+\mathrm{H}[\mathrm{M}+\mathrm{H}]^{+}$: 330.0242, found: 330.0236 .

(4-Bromophenyl)(1-(4-fluorophenyl)-1H-1,2,3-triazol-4-yl) methanol (9I)

Procedure A: the product (9l) was purified by flash chromatography using ethyl acetate/hexane (30:70) as eluent to give a white solid in 55\% yield. mp $105-107^{\circ} \mathrm{C}$; ${ }^{1} \mathrm{H}$ NMR $\left(400 \mathrm{MHz}, \mathrm{CDCl}_{3}\right) \delta$ 7.68-7.63 (m, 3H), $7.52(\mathrm{~d}, J 8.4 \mathrm{~Hz}, 2 \mathrm{H}), 7.39(\mathrm{~d}, J 8.4 \mathrm{~Hz}, 2 \mathrm{H}), 7.20(\mathrm{t}$, $J 9.0 \mathrm{~Hz}, 2 \mathrm{H}), 6.08(\mathrm{~s}, 1 \mathrm{H}) ;{ }^{13} \mathrm{C} \mathrm{NMR}\left(101 \mathrm{MHz}, \mathrm{CDCl}_{3}\right)$ $\delta 163.75,161.27,140.72,133.10,131.77,128.72,128.15$, $126.42,122.61,122.52,122.05,119.77,116.86,116.63$, 68.35 .
Methyl 4-(4-(hydroxy(2-phenylpyridin-3-yl)methyl)$1 H$-1,2,3-triazol-1-yl)benzoate (9m)

Procedure B: the product $(\mathbf{9 m})$ was purified by flash chromatography using ethyl acetate/hexane (20:80 to $40: 60)$ as eluent to give a white solid in $64 \%$ yield. mp 78-80 ${ }^{\circ} \mathrm{C}$; ${ }^{1} \mathrm{H}$ NMR $\left(400 \mathrm{MHz}, \mathrm{CDCl}_{3}\right) \delta 8.60(\mathrm{~d}$, $J 4.4 \mathrm{~Hz}, 1 \mathrm{H}), 8.17(\mathrm{~d}, J 8.7 \mathrm{~Hz}, 2 \mathrm{H}), 8.03(\mathrm{~d}, J 7.9 \mathrm{~Hz}$, $1 \mathrm{H}), 7.76(\mathrm{~d}, J 8.6 \mathrm{~Hz}, 2 \mathrm{H}), 7.70(\mathrm{~s}, 1 \mathrm{H}), 7.55-7.49(\mathrm{~m}$, $2 \mathrm{H}), 7.41-7.37$ (m, 3H), 7.32 (dd, J 7.9, $4.8 \mathrm{~Hz}, 1 \mathrm{H})$, $6.20(\mathrm{~s}, 1 \mathrm{H}), 3.95(\mathrm{~s}, 3 \mathrm{H}) ;{ }^{13} \mathrm{C} \mathrm{NMR}\left(101 \mathrm{MHz}, \mathrm{CDCl}_{3}\right) \delta$ $165.84,157.85,151.57,149.07,139.87,139.24,136.20$, $135.07,131.36,130.39,129.23,128.53,128.39,122.85$, 119.87, 119.48, 65.40, 52.49; HRMS(ESI) $\mathrm{m} / \mathrm{z}$ calcd. for $\mathrm{C}_{22} \mathrm{H}_{18} \mathrm{~N}_{4} \mathrm{O}_{3}+\mathrm{Na}[\mathrm{M}+\mathrm{Na}]^{+}: 409.1379$, found: 409.1270 .

(1-(4-Fluorophenyl)-1 H-1,2,3-triazol-4-yl)(2-phenylpyridin3-yl)methanol (9n)

Procedure A: the product $(\mathbf{9 n})$ was purified by flash chromatography using ethyl acetate/hexane (20:80 to 40:60) as eluent to give a white solid in $70 \%$ yield. mp 74-76 ${ }^{\circ} \mathrm{C}$; ${ }^{1} \mathrm{H}$ NMR $\left(400 \mathrm{MHz}, \mathrm{CDCl}_{3}\right) \delta 8.59(\mathrm{~d}$, $J 3.5 \mathrm{~Hz}, 1 \mathrm{H}), 8.04(\mathrm{~d}, J 7.9 \mathrm{~Hz}, 1 \mathrm{H}), 7.62(\mathrm{dd}, J 9.0,4.6 \mathrm{~Hz}$, $2 \mathrm{H}), 7.56(\mathrm{~s}, 1 \mathrm{H}), 7.52-7.47(\mathrm{~m}, 2 \mathrm{H}), 7.41-7.35(\mathrm{~m}, 3 \mathrm{H})$, 7.31 (dd, J 7.9, $4.8 \mathrm{~Hz}, 1 \mathrm{H}), 7.19$ (t, $J 8.5 \mathrm{~Hz}, 2 \mathrm{H}), 6.18$ (s, 1H); ${ }^{13} \mathrm{C}$ NMR $\left(101 \mathrm{MHz}, \mathrm{CDCl}_{3}\right) \delta 157.75,151.37$, 148.90, 139.24, 136.27, 135.32, 129.23, 128.47, 128.34, $122.83,122.53,122.45,119.86,116.87,116.64,65.20$; HRMS(ESI) $m / z$, calcd. for $\mathrm{C}_{20} \mathrm{H}_{15} \mathrm{FN}_{4} \mathrm{O}+\mathrm{H}[\mathrm{M}+\mathrm{H}]^{+}$: 347.1308, found: 347.1304 .

6-(4-([1,1'-Biphenyl]-2-yl(hydroxy)methyl)-1H-1,2,3-triazol1-yl)-2H-chromen-2-one (9o)

Procedure B: the product $(\mathbf{9 o})$ was purified by flash chromatography using ethyl acetate/hexane (50:50) as eluent to give an orange solid in $48 \%$ yield. $\mathrm{mp} 80-82^{\circ} \mathrm{C}$; ${ }^{1} \mathrm{H}$ NMR $\left(400 \mathrm{MHz}, \mathrm{CDCl}_{3}\right) \delta 7.88(\mathrm{~d}, J 2.4 \mathrm{~Hz}, 1 \mathrm{H})$, $7.80(\mathrm{dd}, J$ 8.9, $2.4 \mathrm{~Hz}, 1 \mathrm{H}), 7.75(\mathrm{~d}, J 9.6 \mathrm{~Hz}, 1 \mathrm{H}), 7.69$ (d, J 7.3 Hz, 2H), 7.48-7.39 (m, 3H), 7.40-7.35 (m, 5H), $7.31(\mathrm{~d}, J 7.3 \mathrm{~Hz}, 1 \mathrm{H}), 6.53(\mathrm{~d}, J 9.6 \mathrm{~Hz}, 1 \mathrm{H}), 6.18$ (s, $1 \mathrm{H}) ;{ }^{13} \mathrm{C}$ NMR $\left(101 \mathrm{MHz}, \mathrm{CDCl}_{3}\right) \delta 159.77,153.53$, $142.44,141.26,140.29,138.98,133.33,130.30,129.46$, $128.32,128.19,128.15,127.45,127.34,123.59,119.55$, 119.44, 118.48, 118.37, 65.93; HRMS(ESI) $\mathrm{m} / \mathrm{z}$, calcd. for $\mathrm{C}_{24} \mathrm{H}_{17} \mathrm{~N}_{3} \mathrm{O}_{3}+\mathrm{Na}[\mathrm{M}+\mathrm{Na}]^{+}:$418.1168, found: 418.1163.

[1,1'-Biphenyl]-2-yl(1-(4-fluorophenyl)-1H-1,2,3-triazol-4-yl) methanol (9p)

Procedure A: the product $(\mathbf{9 p})$ was purified by flash chromatography using ethyl acetate/hexane (30:70) as eluent to give a white solid in $70 \%$ yield. mp $114-116^{\circ} \mathrm{C}$; ${ }^{1} \mathrm{H} \mathrm{NMR}\left(400 \mathrm{MHz}, \mathrm{CDCl}_{3}\right) \delta 7.69(\mathrm{~d}, J 7.2 \mathrm{~Hz}, 1 \mathrm{H})$, 
7.65-7.60 (m, 2H), $7.58(\mathrm{~s}, 1 \mathrm{H})$, 7.45-7.36 (m, 7H), 7.29 (dd, J 7.4, 1.2 Hz, 1H), 7.17 (t, J 8.5 Hz, 2H), 6.15 (s, 1H); ${ }^{13} \mathrm{C}$ NMR $\left(101 \mathrm{MHz}, \mathrm{CDCl}_{3}\right) \delta 163.63,161.15,141.18$, $140.37,139.12,133.22,130.22,129.45,128.27,128.09$, $128.05,127.38,127.36,122.52,122.43,119.90,116.80$, 116.57, 65.81; HRMS(ESI) $m / z$, calcd. for $\mathrm{C}_{21} \mathrm{H}_{16} \mathrm{FN}_{3} \mathrm{O}+\mathrm{H}$ $[\mathrm{M}+\mathrm{H}]^{+}:$346.1356, found: 346.1350 .

[1,1'-Biphenyl]-2-yl(1-(4-methoxyphenyl)-1H-1,2,3-triazol4-yl)methanol (9q)

Procedure A: the product $(\mathbf{9 q})$ was purified by flash chromatography using ethyl acetate/hexane (30:70) as eluent to give a white solid in $30 \%$ yield. mp $108-110^{\circ} \mathrm{C}$; ${ }^{1} \mathrm{H}$ NMR $\left(400 \mathrm{MHz}, \mathrm{CDCl}_{3}\right) \delta 7.72(\mathrm{~d}, J 7.5 \mathrm{~Hz}, 1 \mathrm{H})$, $7.56(\mathrm{~d}, J 8.9 \mathrm{~Hz}, 3 \mathrm{H}), 7.52$ (s, 1H), 7.45-7.33 (m, 9H), $7.30(\mathrm{~d}, J 7.3 \mathrm{~Hz}, 1 \mathrm{H}), 6.99$ (d, J $8.9 \mathrm{~Hz}, 2 \mathrm{H}), 6.15$ (s, 1H), 3.85 (s, 4H); ${ }^{13} \mathrm{C}$ NMR (101 MHz, $\left.\mathrm{CDCl}_{3}\right) \delta 159.81$, $141.21,140.40,139.23,130.45,130.18,129.46,128.27$, 128.07, 127.99, 127.38, 127.36, 122.16, 119.78, 114.73, 65.92, 55.63; HRMS(ESI) $m / z$, calcd. for $\mathrm{C}_{22} \mathrm{H}_{19} \mathrm{~N}_{3} \mathrm{O}_{2}+\mathrm{H}$ $[\mathrm{M}+\mathrm{H}]^{+}: 358.1556$, found: 358.1549 .

1 -(4-(4-([1,1'-Biphenyl]-2-yl(hydroxy)methyl)$1 H$-1,2,3-triazol-1-yl)phenyl)ethanone (9r)

Procedure B: the product (9r) was purified by flash chromatography using ethyl acetate/hexane (30:70) as eluent to give a white solid in $45 \%$ yield. mp $118-120{ }^{\circ} \mathrm{C}$; ${ }^{1} \mathrm{H} \mathrm{NMR}\left(400 \mathrm{MHz}, \mathrm{CDCl}_{3}\right) \delta 8.10(\mathrm{~d}, J 8.7 \mathrm{~Hz}, 2 \mathrm{H}), 7.82$ $(\mathrm{d}, J 8.7 \mathrm{~Hz}, 2 \mathrm{H}), 7.73-7.65(\mathrm{~m}, 2 \mathrm{H}), 7.47-7.42(\mathrm{~m}, 1 \mathrm{H})$, 7.42-7.35 (m, 6H), $7.31(\mathrm{dd}, J 7.5,1.5 \mathrm{~Hz}, 1 \mathrm{H}), 6.18(\mathrm{~s}, 1 \mathrm{H})$, 2.65 (s, 3H); ${ }^{13} \mathrm{C} \mathrm{NMR}\left(101 \mathrm{MHz}, \mathrm{CDCl}_{3}\right) \delta 196.64,141.29$, 140.31, 140.02, 138.97, 136.82, 130.28, 130.07, 129.46, 128.30, 128.17, 128.14, 127.43, 127.33, 119.99, 119.41, 65.98, 26.68; HRMS(ESI) $m / z$, calcd. for $\mathrm{C}_{23} \mathrm{H}_{19} \mathrm{~N}_{3} \mathrm{O}_{2}+\mathrm{H}$ $[\mathrm{M}+\mathrm{H}]^{+}:$370.1556, found: 370.1551 .

\section{Synthesis of $9 H$-fluorenes-1,2,3-triazoles $10 a-10 c$}

Compounds 10a-10c were prepared according to the procedure described by Wang et al. ${ }^{25} \mathrm{In}$ a $20 \mathrm{~mL}$ Schlenk tube, $2.0 \mathrm{~mL}$ dichloroethane were added to a mixture of $\alpha$-hydroxy-1,2,3-triazoles ( $0.2 \mathrm{mmol}, 1.0$ equiv.), $\mathrm{Pd}(\mathrm{OAc})_{2}$ (0.01 mmol, 0.05 equiv., $5 \mathrm{~mol} \%), \mathrm{Na}_{2} \mathrm{CO}_{3}(0.3 \mathrm{mmol}$, 1.5 equiv.), and $\mathrm{PhI}(\mathrm{TFA})_{2}(0.3 \mathrm{mmol}, 1.5$ equiv. $)$ under air. The reaction mixture was stirred at $100{ }^{\circ} \mathrm{C}$ for $36 \mathrm{~h}$. After cooling to room temperature, the reaction mixture was diluted with diethyl ether $(15 \mathrm{~mL})$, filtered through celite, washed with diethyl ether $(2 \times 10 \mathrm{~mL})$, carefully concentrated under vacuum and the residue was purified by column chromatography using ethyl acetate/hexane (20:80) as eluent.
4-(9H-Fluoren-9-yl)-1-(4-fluorophenyl)-1H-1,2,3-triazole (10a)

The product (10a) was obtained as a white solid in $40 \%$ yield. mp 131-132 ${ }^{\circ} \mathrm{C} ;{ }^{1} \mathrm{H}$ NMR $\left(400 \mathrm{MHz}, \mathrm{CDCl}_{3}\right) \delta 7.81$ $(\mathrm{d}, J 7.6 \mathrm{~Hz}, 2 \mathrm{H}), 7.65(\mathrm{~d}, J 7.4 \mathrm{~Hz}, 2 \mathrm{H}), 7.63-7.58(\mathrm{~m}, 2 \mathrm{H})$, 7.43 (t, J 7.5 Hz, 2H), 7.36-7.30 (m, 3H), 7.17-7.11 (m, 2H), $5.51(\mathrm{~s}, 1 \mathrm{H}) ;{ }^{13} \mathrm{C} \mathrm{NMR}\left(101 \mathrm{MHz}, \mathrm{CDCl}_{3}\right) \delta 163.57$, $161.07,149.05,145.17,140.85,127.89,127.57,125.40$, 122.38, 122.30, 120.12, 118.56, 116.70, 116.47, 45.40; HRMS(ESI) $m / z$, calcd. for $\mathrm{C}_{21} \mathrm{H}_{14} \mathrm{FN}_{3}+\mathrm{Na}[\mathrm{M}+\mathrm{Na}]^{+}$: 350.1072, found: 350.1064 .

4-(9H-Fluoren-9-yl)-1-(4-methoxyphenyl)-1H-1,2,3-triazole (10b)

The product (10b) was obtained as a white solid in $30 \%$ yield. mp $124-125{ }^{\circ} \mathrm{C} ;{ }^{1} \mathrm{H}$ NMR $\left(400 \mathrm{MHz}, \mathrm{CDCl}_{3}\right.$ ) $\delta 7.84(\mathrm{~d}, J 7.5 \mathrm{~Hz}, 2 \mathrm{H}), 7.68(\mathrm{~d}, J 7.5 \mathrm{~Hz}, 2 \mathrm{H}), 7.55(\mathrm{~d}$, $J 9.1 \mathrm{~Hz}, 2 \mathrm{H}), 7.45(\mathrm{t}, J 7.2 \mathrm{~Hz}, 2 \mathrm{H}), 7.38-7.33(\mathrm{~m}, 3 \mathrm{H})$, $6.96(\mathrm{~d}, J 9.1 \mathrm{~Hz}, 2 \mathrm{H}), 5.54(\mathrm{~s}, 1 \mathrm{H}), 3.85(\mathrm{~s}, 3 \mathrm{H}) ;{ }^{13} \mathrm{C} \mathrm{NMR}$ $\left(101 \mathrm{MHz}, \mathrm{CDCl}_{3}\right) \delta 159.68,145.35,140.84,130.56$, 127.76, 127.53, 125.44, 122.01, 120.07, 118.57, 114.64, $55.59,45.47$; HRMS(ESI) $m / z$, calcd. for $\mathrm{C}_{22} \mathrm{H}_{17} \mathrm{~N}_{3} \mathrm{O}+\mathrm{Na}$ $[\mathrm{M}+\mathrm{Na}]^{+}:$362.1372, found: 362.1364 .

1-(4-(4-(9H-Fluoren-9-yl)-1H-1,2,3-triazol-1-yl)phenyl) ethanone (10c)

The product (10c) was obtained as a white solid in $25 \%$ yield. ${ }^{1} \mathrm{H}$ NMR (400 MHz, $\left.\mathrm{CDCl}_{3}\right) \delta 8.07(\mathrm{~d}, J 8.7 \mathrm{~Hz}$, 2H), $7.85(\mathrm{~d}, J 7.4 \mathrm{~Hz}, 2 \mathrm{H}), 7.79(\mathrm{~d}, J 8.7 \mathrm{~Hz}, 2 \mathrm{H}), 7.67$ (d, J 7.6 Hz, 2H), $7.50(\mathrm{~s}, 1 \mathrm{H}), 7.47(\mathrm{t}, J 7.5 \mathrm{~Hz}, 2 \mathrm{H}), 7.37$ (t, $J 7.1 \mathrm{~Hz}, 2 \mathrm{H}), 5.55(\mathrm{~s}, 1 \mathrm{H}), 2.65(\mathrm{~s}, 3 \mathrm{H}) ;{ }^{13} \mathrm{C} \mathrm{NMR}$ $\left(101 \mathrm{MHz}, \mathrm{CDCl}_{3}\right) \delta 196.58,149.44,144.99,140.86$, $136.68,129.98,127.96,127.60,125.37,120.17,119.86$, $118.16,45.34,29.70$.

\section{Biological evaluation}

Plasmid corresponding to rat GlyT1b in the pcDNA3 vector was transiently transfected into HEK293 cells using lipofectamine (Invitrogen), as described before..$^{30}$ Twentyfour hours after transfection, cells were replated in polylysinecovered 24-well plates. Subconfluent transfected HEK293 cells growing overnight in Dulbecco's Modified Eagle Medium(DMEM) supplemented with $10 \%$ fetal bovine serum and non-essential amino acids at $37{ }^{\circ} \mathrm{C}$ and $5 \% \mathrm{CO}_{2}$ were washed with (4-(2-hydroxyethyl)-1 piperazineethanesulfonic acid (HEPES)-buffered saline (HBS; $10 \mathrm{mM}$ HEPES-Tris buffer containing $150 \mathrm{mM} \mathrm{NaCl}, 1 \mathrm{mM} \mathrm{CaCl} 2,2.5 \mathrm{mM}$ $\mathrm{KCl}, 2.5 \mathrm{mM} \mathrm{MgSO}_{4}$, and $10 \mathrm{mM}(+)$ D-glucose at $\mathrm{pH} 7.4$ ). Experiments were performed as previously described,$^{30}$ with some modifications. Cells were incubated for $5 \mathrm{~min}$ at $22^{\circ} \mathrm{C}$ 
with the test compounds before addition of $\left[{ }^{3} \mathrm{H}\right]$-glycine. After 5 min incubation with $10 \mu \mathrm{M}\left[{ }^{3} \mathrm{H}\right]$-glycine $(0.01 \mu \mathrm{M}$ stock solution, $49.9 \mathrm{Ci} \mathrm{mmol}^{-1}$, PerkinElmer, Boston, USA, diluted with $10 \mu \mathrm{M}$ unlabeled glycine), the cells were washed twice with $\mathrm{HBS}$ and dissolved in $0.2 \mathrm{~mL}$ of $0.2 \mathrm{M} \mathrm{NaOH}$. Aliquots of each well were taken for scintillation counting (Packard TriCarb 1600 TR liquid scintillation analyzer, PerkinElmer) and protein concentration determination $\left(\mathrm{BCA}^{\mathrm{TM}}\right.$ Protein Assay Kit, Pierce). Results are means \pm standard error (S.E.) of two independent experiments performed in duplicate and are expressed as percentage of control uptake. Note that the glycine accumulation in non-transfected HEK293 cells was subtracted from that of transfected cells in order to measure specifically the glycine uptake due to GlyT1. Statistically significant differences were determined by one-way analysis of variance (ANOVA) followed by Dunett's multiple comparisons test ( $v s$. control). To estimate the concentration causing 50\% inhibition of glycine uptake $\left(\mathrm{IC}_{50}\right)$, compound $\mathbf{9 b}$ was tested at different concentrations and the concentration-response curve was analyzed by non-linear regression (One site - Fit logIC50) using GraphPad Prism 5.0. ${ }^{31}$ This experiment was performed in duplicate and replicated twice $(n=3)$.

\section{Supplementary Information}

Supplementary data ( ${ }^{1} \mathrm{H}$ NMR and ${ }^{13} \mathrm{C}$ NMR spectra) are available free of charge at http://jbcs.sbq.org.br as PDF file.

\section{Acknowledgments}

This study was financed in part by the Coordenação de Aperfeiçoamento de Pessoal de Nível Superior, Brazil (CAPES), Finance Code 001.

\section{Author Contributions}

Veronica D. da Silva, Rafaela R. Silva, João Gonçalves Neto were responsible for the data curation and investigation; François Noël and Camilla D. Buarque for the formal analysis, funding acquisition, conceptualization and writing review and editing; Camilla D. Buarque was also responsible for the project administration, resources, validation and visualization; Veronica D. da Silva, Rafaela R. Silva for the writing of original draft; Beatriz López-Corcuera, Marilia Z. Guimarães for the writing review and editing.

\section{References}

1. Mady, M. F.; Awad, G. E. A.; Jørgensen, K. B.; Eur. J. Med. Chem. 2014, 84, 433.
2. Yadav, P.; Lal, K.; Kumar, A.; Guru, S. K.; Jaglan, S.; Bhushan, S.; Eur. J. Med. Chem. 2017, 126, 944.

3. Mohammed, I.; Kummetha, I. R.; Singh, G.; Sharova, N.; Lichinchi, G.; Dang, J.; Stevenson, M.; Rana, T. M.; J. Med. Chem. 2016, 59, 7677.

4. Keck, T. M.; Banala, A. K.; Slack, R. D.; Burzynski, C.; Bonifazi, A.; Okunola-Bakare, O. M.; Moore, M.; Deschamps, J. R.; Rais, R.; Slusher, B. S.; Newman, A. H.; Bioorg. Med. Chem. 2015, 23, 4000.

5. Ayati, A.; Emami, S.; Foroumadi, A.; Eur. J. Med. Chem. 2016, 109,380 .

6. Caliendo, G.; Fiorino, F.; Perissutti, E.; Severino, B.; Scolaro, D.; Gessi, S.; Cattabriga, E.; Borea, P. A.; Santagada, V.; Eur. J. Pharm. Sci. 2002, 16, 15.

7. Harvey, R. J.; Yee, B. K.; Nat. Rev. Drug Discovery 2013, 12 , 866.

8. Sugane, T.; Tobe, T.; Hamaguchi, W.; Shimada, I.; Maeno, K.; Miyata, J.; Suzuki, T.; Kimizuka, T.; Sakamoto, S.; Tsukamoto, S.; J. Med. Chem. 2013, 56, 5744.

9. Thomson, J. L.; Blackaby, W. P.; Jennings, A. S. R.; Goodacre, S. C.; Pike, A.; Thomas, S.; Brown, T. A.; Smith, A.; Pillai, G.; Street, L. J.; Lewis, R. T.; Bioorg. Med. Chem. Lett. 2009, 19, 2235 .

10. Atkinson, B. N.; Bell, S. C.; De Vivo, M.; Kowalski, L. R.; Lechner, S. M.; Ognyanov, V. I.; Tham, C. S.; Tsai, C.; Jia, J.; Ashton, D.; Klitenick, M. A.; Mol. Pharmacol. 2001, 60, 1414.

11. Singer, P.; Dubroqua, S.; Yee, B.; Curr. Pharm. Des. 2015, 21 , 3771.

12. Alberati, D.; Moreau, J.-L.; Lengyel, J.; Hauser, N.; Mory, R.; Borroni, E.; Pinard, E.; Knoflach, F.; Schlotterbeck, G.; Hainzl, D.; Wettstein, J. G.; Neuropharmacology 2012, 62, 1152.

13. Lowe, J. A.; Hou, X.; Schmidt, C.; Tingley, F. D.; McHardy, S.; Kalman, M.; DeNinno, S.; Sanner, M.; Ward, K.; Lebel, L.; Tunucci, D.; Valentine, J.; Bioorg. Med. Chem. Lett. 2009, 19, 2974.

14. Lowe, J.; Drozda, S.; Qian, W.; Peakman, M.-C.; Liu, J.; Gibbs, J.; Harms, J.; Schmidt, C.; Fisher, K.; Strick, C.; Schmidt, A.; Vanase, M.; Lebel, L.; Bioorg. Med. Chem. Lett. 2007, 17, 1675.

15. Cioffi, C. L.; Liu, S.; Wolf, M. A.; Guzzo, P. R.; Sadalapure, K.; Parthasarathy, V.; Loong, D. T. J.; Maeng, J.-H.; Carulli, E.; Fang, X.; Karunakaran, K.; Matta, L.; Choo, S. H.; Panduga, S.; Buckle, R. N.; Davis, R. N.; Sakwa, S. A.; Gupta, P.; Sargent, B. J.; Moore, N. A.; Luche, M. M.; Carr, G. J.; Khmelnitsky, Y. L.; Ismail, J.; Chung, M.; Bai, M.; Leong, W. Y.; Sachdev, N.; Swaminathan, S.; Mhyre, A. J.; J. Med. Chem. 2016, 59, 8473.

16. Rostovtsev, V. V.; Green, L. G.; Fokin, V. V.; Sharpless, K. B.; Angew. Chem., Int. Ed. 2002, 41, 2596.

17. Kolb, H. C.; Sharpless, B.; Drug Discovery Today 2003, 8, 1128.

18. da Silva, V. D.; de Faria, B. M.; Colombo, E.; Ascari, L.; Freitas, G. P. A.; Flores, L. S.; Cordeiro, Y.; Romão, L.; Buarque, C. D.; Bioorg. Chem. 2019, 83, 87. 
19. Shi, Y.; Gao, S.; Tetrahedron 2016, 72, 1717.

20. Kaiser, R. P.; Caivano, I.; Kotora, M.; Tetrahedron 2019, 75, 2981.

21. Grimes, K.; Gupte, A.; Aldrich, C.; Synthesis 2010, 2010, 1441.

22. Tao, C.-Z.; Cui, X.; Li, J.; Liu, A.-X.; Liu, L.; Guo, Q.-X.; Tetrahedron Lett. 2007, 48, 3525.

23. Oikawa, A.; Kindaichi, G.; Shimotori, Y.; Hoshi, M.; Tetrahedron 2016, 72, 4205.

24. Hein, J. E.; Fokin, V. V.; Chem. Soc. Rev. 2010, 39, 1302.

25. Wang, X.; Lu, Y.; Dai, H.; Yu, J.; J. Am. Chem. Soc. 2010, 132, 12203.
26. Li, G.; Wang, E.; Chen, H.; Li, H.; Liu, Y.; Wang, P. G.; Tetrahedron 2008, 64, 9033.

27. Killander, D.; Sterner, O.; Eur. J. Org. Chem. 2014, 2014, 6507.

28. Wienhold, F.; Claes, D.; Graczyk, K.; Maison, W.; Synthesis 2011, 4059.

29. Wilkening, I.; del Signore, G.; Hackenberger, C. P. R.; Chem. Commun. 2011, 47, 349.

30. Herdon, H. J.; Godfrey, F. M.; Brown, A. M.; Coulton, S.; Evans, J. R.; Cairns, W. J.; Neuropharmacology 2001, 41, 88.

31. GraphPad Prism 5.0; GraphPad Software, Inc., CA, USA, 2014.

Submitted: September 13, 2019

Published online: January 28, 2020 